\title{
The myth of youth Hermias and his dolphin at Iasos in Caria
}

\author{
Mehmet Turgut
}

Published online: 30 July 2009

(C) Springer-Verlag 2009

Iasos (Iasus or Iassus), an ancient city of Caria in the southwestern corner of Asia Minor, is situated on the north side of the Iasian or Bargylian gulf between Poseidion and the peninsula of Myndus and was occupied from the Early Bronze Age until the sixteenth century A.D. (Fig. 1; http:// en.wikipedia.org/wiki/Iasus,_Caria, http://images.google. com.tr/images?ndsp=20\&um $=1 \& \mathrm{hl}=$ tr $\& \mathrm{q}=\mathrm{ias}$ os + and + map\&start $=0 \& s a=N)[1,2]$. After the Sicilian expedition of the Athenians, Iasus was attacked by the Spartans and then it was compelled by the Romans to restore it (http://en. wikipedia.org/wiki/Iasus,_Caria). The site lies on a small island close to mainland at the modern village of Kiy1 Kışlacık (Asın Kale or Asın Kurin), Milas, Muğla, Turkey. It has been excavated by an Italian expedition team, originally directed by Doro Levi (http://www.misart.it).

There is a famous myth on a youth riding on a dolphin, which has been assigned to Iasos in Caria which was the fascinating country south of the river Meander [1, 3, 4]. In history, it is mentioned that the people living in Iasos city were supplied with fish and Hermias was the only kid of a mum. The kids kept trying to get him outside to get in the sea, but he refused because his mum would not let him. Afterwards, the kids started making fun of him, and finally, the mother agreed, but she asked him to not wander out too

M. Turgut $(\bowtie)$

Department of Neurosurgery, School of Medicine,

Adnan Menderes University,

09100 Aydin, Turkey

e-mail: drmturgut@yahoo.com far. The kids, including Hermias, firstly went to palaestria of Iasos city to play games and then they went to the sea to swim. At the end of the day, all the kids, except Hermias, returned to the shore. Everybody looked around for him in vain. According to the myth, much later, a fisherman saw him coming towards the shore on a dolphin. They both landed and were found to be dead. It is said that, although it is not perfectly clear, Hermias had some relationship with the dolphin, but he died whilst playing with him due to falling on the spike of the dolphin's fin. Therefore, it is believed that the dolphin decided to depart from life himself after it carried him to shore, and the dolphin then died of grief. The people living in Carian city Iasos constructed a stele of a youth riding the dolphin, as a commemoration of this unfortunate incident. In addition, Hermias was demonstrated as lying on dolphin's back on coins (Fig. 2; http:// www.tomcederlind.com/catalog/147/PDFs/page07.pdf).

Recently, a statuary of Hermias as a boy standing on his hands on dolphin's back was found in an excavation in ancient Nysa, a Carian city in the east of Tralles, as illustrated in Fig. 3 [5]. This myth emphasises the love between the unfortunate Iasian boy named Hermias and his dolphin. Currently, the story is taken as a clear historical basis of great friendship between humankind and dolphin in the world. More importantly, the myth clearly suggests that it is difficult for the mankind to explain or accept the death of a child, because it probably signifies the loss of hopes, dreams and future. After a child's death, parents will continually perceive the blank place in their hearts caused by such a devastating experience. It is widely accepted that the creation of a myth indeed is a way to overcome the grief of the child's death. 
Fig. 1 A map showing ancient Iasos town and the Bargylian gulf of Caria in the southwestern corner of Asia Minor (http:// images.google.com.tr/images? ndsp $=20 \& u m=1 \& h l=\operatorname{tr} \& q=$ iasos + and + map \&start $=0 \&$ sa $=$ N)

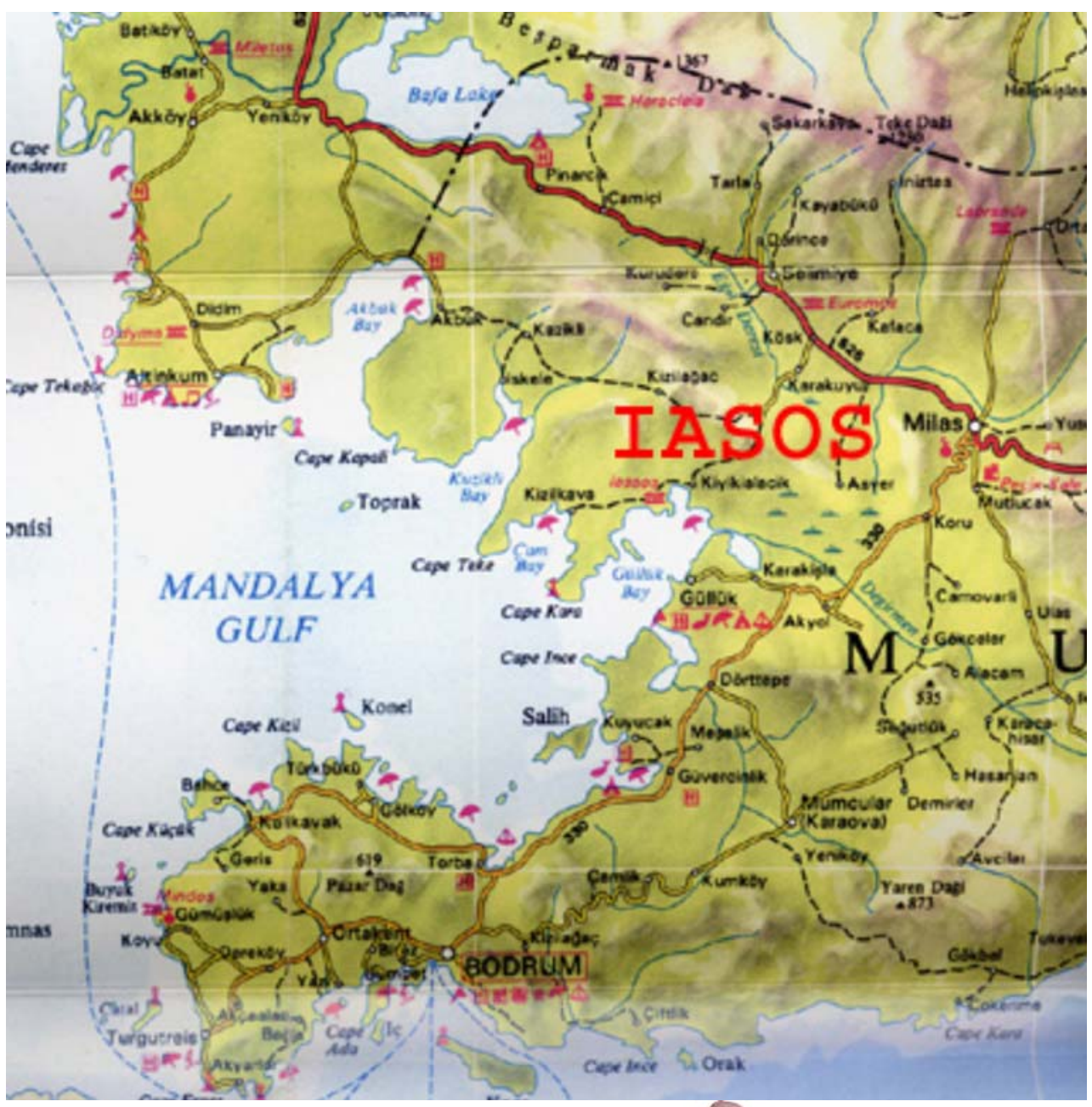

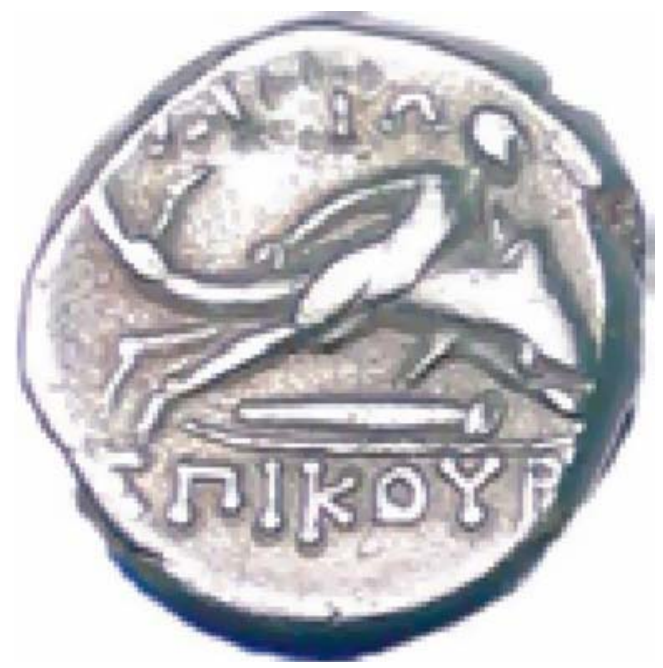

Fig. 2 An Iasian coin depicting the youth Hermias riding on the dolphin is mentioned as a sign of friendship (http://www.tomcederlind. com/catalog/147/PDFs/page07.pdf)

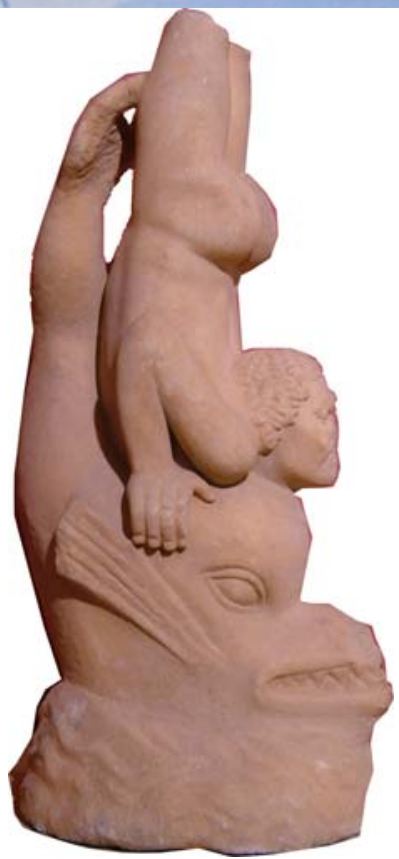

Fig. 3 A unique view of Iasian boy Hermias with curly hair standing on his hands on dolphin's back (used as cover picture). From the private collection of my fellow townsman Mustafa Kenan Özkan, art historian, at Aydın Museum of Ministry of Culture and Tourism of Republic of Turkey 


\section{References}

1. Bean GE (1971) Turkey beyond the meander. Murray, London, p 21

2. Schmitz L (1857) A manual of ancient geography. Blanchard and Lea, Philadelphia, pp 285-289
3. Akarca A, Akarca T (1954) Milas: its geography, history and archeology (in Turkish). İstanbul Matbaas1, İstanbul, p 154

4. Baldoni D, Franco C, Belli P, Berti F (2004) Carian Iasos. Homer archaelogical guides 2. Homer Kitabevi, İstanbul, p 38

5. İdil V (1999) Nysa and Acharaca (in Turkish). Yașar Eğitim ve Kültür Yayınları, İstanbul, p 11 